\title{
Arousing Students' Interests through Expansive Learning-the Cultivation of Students' Core Competences in the Teaching of English Reading in Vocational Colleges
}

\author{
Wang Qian \\ Beijing Polytechnic \\ Beijing, China
}

\begin{abstract}
Under the circumstance of quality-oriented education, the cultivation of students' all-round competence has been given special emphasis in education. Similarly, English teaching in vocational colleges also needs to stress the development of students' core competences, and teachers are expected to combine three dimensions, namely knowledge and skills, emotional attitude and value, as well as process and method, to jointly serve the goal of cultivating students' core competences. Therefore, in teaching, teachers should be based on the English course teaching objectives for higher vocational colleges described in the new curriculum standard, permeate cultural education into course education, and regard crosscultural communicative competence as a starting point so as to help students foster English subject quality. Starting from the status quo of English reading teaching in higher vocational colleges and based on the subject quality and the humanistic quality and language development requirements, this paper tries to comprehensively set up the reading difficulty, guide students to read excellent articles and enable them to independently think and judge during the reading process, thus encouraging them to express their points of view in English and realizing innovative expression. By doing so, it can make students have a better understanding about English culture and enhance their English skills and core competences.
\end{abstract}

Keywords-Vocational College; Teaching of English Reading; Core Competences

\section{INTRODUCTION}

The core competences primarily refer to students' development in language competence, cultural personality, trait of thinking and learning competence, and its purpose lies in enhancing students' recognition for culture, science spirit, aesthetic taste and practice and innovation [1]. In terms of the teaching of English reading in higher vocational colleges, the cultivation of students' core competences requires the reasonable arrangement of core teaching module. Besides, teachers should play a guiding role with rational evaluation and teaching to incite students' learning interests and initiatives, encouraging them to express themselves and increasing their English skills and learning efficiency.

\section{ENRICHING THE READING MATERIALS IN VOCATIONAL COLLEGES AND ENHANCING STUDENTS' UNDERSTANDING AND EXPRESSION COMPETENCES}

Thus, teachers need to take advantage of students' learning attitudes throughout the teaching process. Emphasis shall be put in the training of students' understanding competence. In order to realize that, teachers should study English texts in depth, design interesting reading activity, and change the conventional simple form of text reading. Except for enriching the reading materials, teachers also need to arrange some explosive experiments, and utilize the teaching method of explosive reading to realize interactive communication among students with collision of ideas and to stimulate their initiative for English reading [2]. At the same time, students are able to associate with the English knowledge that they have learned to broaden their reading mindset, remaining a relatively higher initiative for reading and actively exploding the reading questions. The setting of reading difficulty should be in gradient, and the reading difficulty should be uplifted gradually to make sure it is challenging for students. For instance, as for the explanation of business etiquette, teachers can choose to start with the comparison between the American etiquette and the British etiquette, or base on the reading of some religious books by providing corresponding reading materials --- taking books about Muslim as the reading materials, and are able to introduce cultures in different countries through such kind of comparisons of various etiquettes and on the basis of the core theme of "International Business Etiquette". [3] As such, the communication model among diverse cultures can be realized in English teaching, and meanwhile, the cultivation of core English competences can be accomplished. Therefore, in the English education of higher vocational colleges, teachers shall select suitable text theme background and core information in accordance with students' learning interests and enthusiasm to promote students' reading interests and boost their reading level, and to enhance their core competences and language expressive ability by unfolding the reading progress through the reading texts. 
In addition, teachers should also fully consider the individual differences among students, and select different reading materials according students' different English level and interests. "Grimm's Fairy Tales", "Jane Eyre" or other famous literary works for students who have a fancy for literature and "Family Album USA", "Greek mythology" and other reading materials for those who want to know more western customs and practices. In order to enhance students' interests, teachers should try to create a positive English learning atmosphere through organizing English corner in English courses and dividing students into different learning group based on their interests, and handing out famous literary works, English newspapers, or reading journals to corresponding groups to meet the diversified reading needs among students, and at the same time, it is able to promote the mutual supervision, coordination and communication among students [4]. By doing so, it can extend the teaching of English reading in higher vocational colleges to communication after class. Besides, teachers can also present a book list for elective reading according to students' classroom performance, and provide corresponding reading tasks to improve the combination of reading in and out of class, enrich the reading materials and to facilitate the cultivation of core English competences.

\section{ARRANGING THEME ACTIVITIES TO IMPROVE STUDENTS' LANGUAGE EXPRESSIVE ABILITY}

The language expressive ability is an essential point of both core competence and English reading learning. The basic five aspects of English teaching include listening, speaking, reading, writing and translation, and language competence, as the key and basis of foreign language learning, serves as the premise for the development of other four competences. As for language competence acting as the core competence in the discipline of English, the English curriculum standard for vocational colleges expressly points out that teachers should create meaningful language learning situation for students, and expand the cultural knowledge and the language itself in English learning through language communication, language expression and other methods and centering around emotion, attitude and value. As a result, English teachers shall consider students' understanding depth for theme language and texts, attach importance to the guiding of expansion for students' thinking, and promote students' diversified reading through divergent thinking to enhance students' language learning efficiency. The whole class shall be based on the exploration of thematic meaning, realizing the integration of learning content and learning resources and optimizing students' language expressive ability.

English teachers shall strictly implement the peopleoriented education philosophy of strengthening moral education and cultivating people, improve students' core competences through moral education and culture, promote students' communication competence and enhance their core language competences and overall qualities through the English reading teaching in vocational colleges. When arranging theme activities. The thematic meaning of exploration should be firstly identified, English teachers can begin with the teaching of theme vocabulary in each unit and enhance students' understanding for the theme vocabulary in exploratory language context. Here are the main measures:

\section{A. Simulation interview and role play}

English teachers should randomly select students and form different groups, and assign different role for students in line with their interests and language expressive ability. Teachers should represent the interview situation for students, and enable them to activate their hearing, listening and other senses and maximize their abilities, including listening, speaking and reading, under certain "situations" and through interpersonal activities of specific roles, and to construct language situational activities. In the English teaching of vocational colleges, English teacher are able to randomly carry out language communication construction around the interview theme, establish the interview activities related to the teaching content, and conduct unit theme interview activities according to the content of the unit. Stress should be given to the use of the key word in the unit in communication, which will facilitate the simulation of the role's language, body or other various interactions, realizing the multiple transmission of information. Such kind of activities are capable of not only providing chance for other students to directly learn knowledge and observe language expressive methods, but also training the participant students' language interpersonal ability and mastering a wide range of language communicative language.

\section{B. Scenario simulation and mining the in-depth implication in texts}

Students tend to encounter some reading obstacles in reading, and teachers are able to ask students to simulate and re-present the reading situation in the reading texts through scenario simulation, offers students the chance to actually experience the situation to develop their way of thinking and enhance their trait of thinking. For example, in the course of the "A few Simples of English Poems", English teachers are able to let students simulate the way of reading ancient pomes and to rad or sing these English pomes. Or they can choose to apply multimedia and play videos or radios in class. Then, there could be some communication activities between the teacher and students, teachers could set up some dialogues in advance, guide students through putting forward questions in a heuristically way to guide students to understand, or even guess the meaning of new words, to make students experience the different features among different pomes in the real situations. Communications and scenario simulations in the process of student finding answers to reading questions are able to allow students to independently analyze and expand their way of thinking according to their individual features, and deepen their understanding for these pomes in accordance with their unique feelings when reading pomes. And finally, students need to review the knowledge learned and find out the topic sentence in order to solve their reading disorders and enhance their trait of thinking. 


\section{CREATING READING SITUATIONS AND IMPROVING STUDENTS' LEARNING ABILITY}

The creating of reading situations means that letting students to read with the related knowledge of language and culture background so as to achieve students' more comprehensive understanding for other counties' culture and customs. Taking the lessons of "Cultural Relic" and "Unit 5 Music" for example, English teachers can utilize multimedia or other teaching methods and show students the related pictures, videos, radios and courseware downloaded from the Internet in class to create an excellent teaching and learning environment in classroom, and to deepen students' understanding for cultural background and etiquette in language communication by virtue of their hearing and listening. Students can have a discuss about the topic of "Cultural Relic", and teachers should guide the student by enumerate some famous culture relic in China, such as The Great Wall and The Forbidden City, and then to let students have a free speaking and point our other famous domestic historical sites, which can not merely expand students' cognitive perspective, realizing cultural education, increasing the penetration of cultural knowledge in English teaching and emphasizing the English core quality of cultivating students, and offer chance for students to practice freely, enhance their expressive ability and ability of drawing inferences about other cases from one instance, enforce learning ability and comprehensively increase their core competences.

In the development of learning ability, students' consciousness of independent studying shall also be enhanced, and English teachers need to construct the "self-reading" platform to improve students' learning quality and efficiency [5]. According to students' reading interests, teachers shall encourage students to read by themselves by taking the reading text as an introduction material. Stress should be attached on students' reading and speaking competence, and teacher shall get back to the theory of taking ability as the key factor, pay attention to the establishment of a clear English learning standard, the development of students' professional competence, and stick to the concept of "ability as the key factor", inciting students' reading initiatives. English teachers should raise questions that students may meet in practical reading, and ask different question according to students' differences in reading in a progressive way and make sure students' thinking development is on the rise by raising questions from the shallower to the deeper. For example, the following questions: 1 , How many men did the woman see in her front garden? So that the question 2 and question 3 can be Why did she invite them in since she didn't know any of them? Or why did Wealth and Success go into the house with Love? When designing these questions, English teachers shall pay attention to the diversified English levels among students, and make sure all students are able to participate in the exploration process of questions, creating a good learning atmosphere and learning situations, promoting the realization of students' independent learning and exploration so as to enhance their all-round learning competence and optimize their trait of thinking.

\section{IMPROVING TEACHING ASSESSMENT AND CREATING A RELAXED ATMOSPHERE}

In the new times, the main body of class and teaching assessment shall be the learning of students, which should pay attention to both the learning results of students and the learning process. Thus, it embraces class assessment, atmosphere and process assessment and summative assessment. Teachers shall make students collect information, understand and grasp knowledge, and give a feedback on the shortcomings of learning. And the class and teaching assessment shall be viewed as a key point in the later stage of reading teaching. By regarding the cognitive development of students as the basis, teachers shall stimulate students' learning initiatives and formulate a scientific and humanized assessment plan, changing the traditional assessment method that takes students record as the chief standard, comprehensively and truly reflecting students' reading level and both acknowledging students' development and making students aware of their drawbacks in reading competence. In the reading assessment, that for English teachers' initiatives is able to promote students' language thinking and improve the formation of students' language awareness, which are beneficial for the construction of a harmonious relation between students and teachers. Therefore, English teachers should use humorous language to create a relaxed and pleasant environment for student to deepen their reading knowledge and promote the the cultivation of core competences.

\section{CONCLUSION}

In conclusion, the cultivation of students' core competences in the teaching of English reading in vocational colleges should focus the enhancing of students' speaking competence, understanding and communicative competence as well as learning competence, creating an excellent teaching situation and a good learning atmosphere for students and implementing after-reading assessment to realize the cultural education and the whole-process education.

\section{REFERENCES}

[1] Lin Yang, Dan Li. Practical exploration of college English reading teaching on the basis of core competences [J]. Modernization of education, 2018,5(11):168-169.

[2] Linqing Chen. Arousing Students' interests through Expansive Learning --- the Cultivation of Students' core Competences in the Teaching of English Reading in Higher Vocational Colleges[J]. Science \& Technology Industry Parks, 2018(09):77.

[3] Shenghua Huang, Zhongyu Jiang. Research on English reading and vocabulary teaching in high school from the perspective of core competences[J]. English teacher, 2018(16):131-136.

[4] Yiqun Zhou. Teaching strategies of English reading in higher vocational colleges based on "Core Competences" [J]. Modern professional education, 2017(29):14.

[5] Fengfeng He. How to cultivate core competences in English reading teaching in high school[J]. Junior Kids English, 2018(34):44. 